\title{
200.000 IU of vitamin D does not reduce resting Blood Pressure and Inhibit Post-Exercise Hypotension in elderly women: a pilot study
}

\author{
MARIA DA CONCEIÇÃO R. GONÇALVES, MANOEL MIRANDA NETO, ISA G.M. \\ CAVALCANTE, VITTÓRIA R.R.J. SEBADELHE, MICHELE F. SOUZA, JULIANA \\ P.R. NEVES, FLAVIA T.L. SOUZA, RENATA L. TAVARES, MATHEUS S. COSTA \& \\ ALEXANDRE S. SILVA
}

\begin{abstract}
Given the scarcity of studies with elderly and the existence of studies investigating the effect of vitamin D supplementation in PEH (post exercise hypotension), this study evaluated the effect of a single megadose of vitamin $D$ on resting blood pressure (RBP) and post-exercise hypotension (PEH) in the elderly. 11 hypertensive elderly women (70.3 \pm 1.7 years) received a single megadose of $200.000 \mathrm{IU}$ of cholecalciferol or a placebo, orally, through capsules. On day 7 , the subjects performed 30 minutes of aerobic exercise with blood pressure measurement before exercise and every 10 minutes after exercise during 60 minutes, besides cardiac autonomic modulation. RBP did not significantly change. Exercise promoted significant systolic PEH only in one moment post exercise in treated group and in the placebo group promoted significant systolic PEH at four moments. Significant diastolic PEH did not occur in any of the groups. Sympathovagal activity increased at post exercise balance in supplemented subjects at $20 \mathrm{~min}, 40 \mathrm{~min}, 50 \mathrm{~min}$ and 60 min when compared to rest; this increase was not observed in the placebo. A megadose of vitamin D did not reduce RBP, promoted partial inhibition of systolic PEH and increased sympathovagal balance.
\end{abstract}

Key words: aerobic exercise, aged, hypertension, hypotension, cholecalciferol.

\section{INTRODUCTION}

Hypovitaminosis D is considered a worldwide epidemic (Holick \& Chen 2008), especially in those individuals belonging to risk groups such as children, pregnant women and the elderly (Bruyére et al. 2014). Beyond well-known role of vitamin D in bone metabolism (Lips \& Van Schoor 2011), the involvement of this micronutrient in chronic non-communicable diseases has been recently described (Holick 2007, Schuch et al. 2009). Data from the Health Professionals Follow-up Study (HPFS) and the Nurses Health
Study showed a negative relationship between serum vitamin D levels and hypertension, which is independent of age, body mass index (BMI), physical activity and ethnicity (Forman 2007). This relationship, however, does not apply to the elderly according to a data review and metaanalysis of prospective (58.268 people) and cross sectional (90.553 people) studies (Ke et al. 2015).

On the other hand, vitamin D supplementation has been associated with discrete beneficial effects on blood pressure and endothelial function in cardiovascular diseases (Witham et al. 2009), including protocols with megadoses of $100.000 \mathrm{IU}$ 
to 200.000 IU (Judd et al. 2010, Miles 2010). However, there is no consensus about hypotensive effect of vitamin $D$ since other studies have shown no reduction in blood pressure, according to a review performed by Kunutsor et al. (2014) which showed no significant reduction or, clinically, discrete and significant heterogeneity in the responses of the original studies.

In addition to the effect of vitamin D on blood pressure being somewhat controversial, the effects of supplementation in the elderly are even less clear because limited amount of research with this population. Therefore, it is necessary to study the effects of vitamin D supplementation on the elderly, because it is known that older people may respond differently to young people regarding the absorption, metabolism and plasma half-life of ingested substances (Lanske \& Razzaque 2007).

In addition to reducing resting blood pressure, our research group has questioned whether the hypotensive effect caused by vitamin D could be associated with the effects of exercise to promote blood pressure reduction following physical exercise, a phenomenon known as post exercise hypotension (PEH). This phenomenon is a decrease in blood pressure compared to pre-exercise values in the first minutes after the elderly undergo a session of aerobic exercise (Brito et al. 2011). PEH is the result of a synergy between several mechanisms related to decreased cardiac output, sym pathetic nerve activity, peripheral vascular resistance and histamine receptor activation (Halliwill et al. 2013). It has also been associated with a reduction in the synthesis of vasopressin, norepinephrine, renin and angiotensin II production (Pardono et al. 2012), which are mechanisms that have been presented in studies where vitamin D supplementation promoted a reduction in blood pressure (Geleijnse 2010). Therefore, the hypothesis of the present study was that an acute megadose of vitamin $D$ reduces resting blood pressure and potentiates the post exercise hypotension in elderly hypertensive women.

Given the scarcity of studies with elderly people and the existence of studies investigating the effect of vitamin D supplementation in PEH, this study aimed to test whether a megadose of 200.000 IU of vitamin D could reduce the resting blood pressure of elderly hypertensive women, enhance PEH and ameliorate autonomic nervous modulation in those previously diagnosed with vitamin D insufficiency.

\section{MATERIALS AND METHODS}

\section{Study subjects and ethical issues}

The study was a placebo-controlled, double blind, randomized, clinical trial study based on a previous study that had determined the prevalence of vitamin $\mathrm{D}$ insufficiency in a population of elderly hypertensives (Neves et al. 2012). Out of a total of 91 elderlies, 81 were women (89\%), and 10 were men (11\%); 30 elderlies from both sex was classified as insufficiency / deficiency of vitamin D (values of 25-hydroxyvitamin D $<29 \mathrm{ng} / \mathrm{ml}$ ) (Holick et al. 2011).

The following inclusion criteria were applied: having high blood pressure and being under treatment; having blood pressure $<160 / 100 \mathrm{~mm}$ $\mathrm{Hg}$, be female sex, have agreed to participate and completed all data collection. Additional inclusion criteria for the study were be over 60 years old, have medium cardiovascular risk according to Risko test - Michigan Heart Association - and do no use of medication or supplements that contain vitamin D, however, they could use any class of antihypertensive drugs. The elderly that demonstrated the inability for performing physical exercise sessions in the adaptation phase were excluded from the study. After applying the inclusion and 
exclusion criteria, 11 women were eligible to participate in the study.

Initially, the 11 women were randomly allocated into two groups [experimental $(n=$ 6) and placebo $(n=5)]$ (www.randomizer.com) to receive a single megadose 200.000 IU of cholecalciferol (experimental) or cornstarch (placebo), respectively, orally, in capsules. Three to six weeks after completing this protocol, the subjects in the placebo group started the protocol with the administration of a megadose of cholecalciferol. Thus, 11 volunteers completed the experimental protocol (70.3 \pm 1.7 years). The group that started the protocol with vitamin D (cholecalciferol) supplementation did not cross over to the placebo group because of the effects of the treatments, thus, the placebo group continued with 5 volunteers. The sample size was not statistically determined. In order to solve doubts regarding the ability of the sample size to answer the study question, was performed a posteriori effect size calculation was performed, which revealed a value of 1.01 and a minimum sample size of eight subjects for resting blood pressure.

The study was approved by the Research Ethics Committee of the Hospital Universitário Lauro Wanderley (HULW) of the Universidade Federal da Paraíba, in accordance with Resolution No. 466/12 of the Conselho Nacional de Saúde / Ministério da Saúde, which regulates the ethics of research on humans in Brazil (Protocol No. $684 / 10$ ). All subjects were previously informed of the purposes and methods of the study and were asked to sign a consent form.

\section{Experimental design}

As can be seen in Figure 1, home visits were carried out to measure blood pressure at rest and to administer the vitamin D3 supplementation or the placebo. Five days later, another home visit was conducted to verify resting blood pressure, and seven days after the supplementation, elderly patients performed an exercise protocol at the hospital. Prior to the exercise sessions, blood pressure, cardiac autonomic nervous activity and resting heart rate were measured. After these sessions, the elderly remained seated for 60 minutes, and new blood pressure and cardiac autonomic nervous activity measurements were recorded every 10 minutes.

\section{Consumption of foods rich in vitamin D}

All participants were instructed do not change neither their eating habits nor their sun exposure and do not consume supplements containing vitamin D during participation in this research. To verify these considerations, volunteers answered a nutrition survey carried out by quantitative food frequency questionnaire intake (QQFCA), which was previously validated from three 24hour recalls applied at different time intervals (Lima et al. 2007). The weekly consumption of eggs, fish, skimmed milk and whole milk by the volunteers was evaluated. The frequency of consumption was classified as never, sometimes (1-3X / week) and frequently ( $\geq 4 \mathrm{x} /$ week).

\section{Exercise protocol}

The subjects previously performed one or two sessions of adaptation to exercise on a stationary bike with light intensity to maintain exercising for 30 minutes without showing discomfort, which was understood as a subjective perception of effort greater than 14 on the scale proposed by Borg \& Noble (1974). After the last adaptation session, they were instructed not to perform exercise or intense efforts 48 hours before the experimental study session. They were subjected to two 30-minute sessions of aerobic exercise on a stationary bike with a predetermined intensity between 60 and $80 \%$ of their maximum heart rate or a subjective perception of effort between 


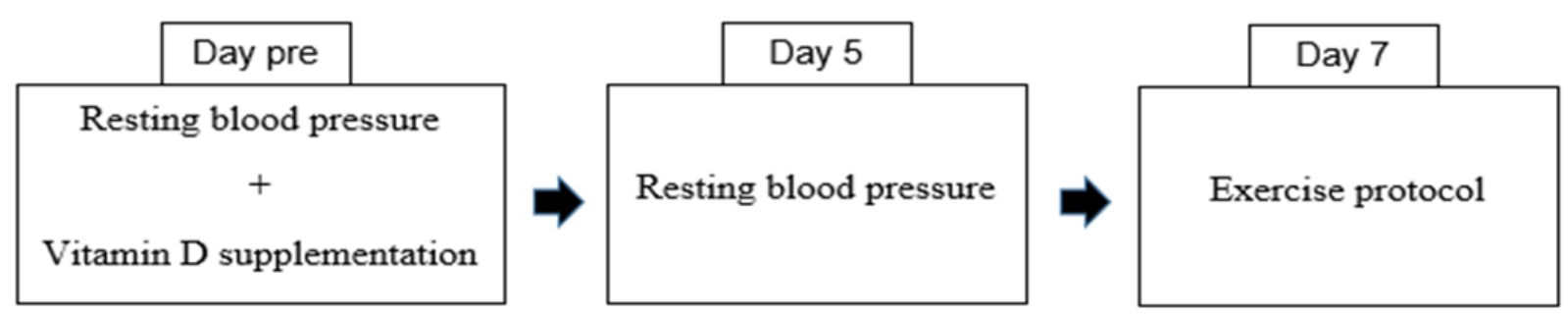

\section{Exercise protocol}

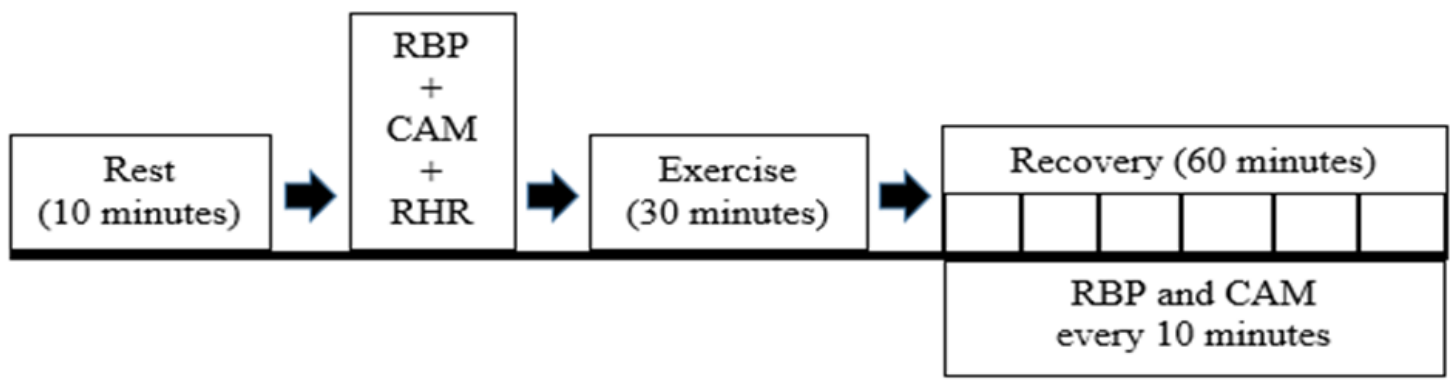

Figure 1. Experimental design. RBP (resting blood pressure), CAM (cardiac autonomic modulation), RHR (resting heart rate).

11 and 14 on subjective perception of effort scale proposed by Borg \& Noble (1974). Exercise intensity monitoring was done every 5 minutes. The modality (aerobic walking exercise), duration and intensity were determined based on a literature review that indicates aerobic exercise as the most effective to promote PEH (lasting between 20 and 60 minutes and moderate intensity) (Brito et al. 2014).

\section{Blood Pressure measurements}

Moments before the administration of the supplementation or the placebo, a triplicate measure of blood pressure (BP) at rest were performed (day pre). New measurements were performed at rest in the fifth days after supplementation (day 5). On the seventh day after supplementation, BP measurements were made pre- and post-exercise (day 7). The pre-exercise measurement was performed after at least 10 minutes of rest, as the volunteer remained seated. Further measures were taken immediately after exercise and during 60 minutes of recovery, in 10-minute intervals. An aneroid sphygmomanometer Missouri brand, which was previously calibrated against a mercury column, and a stethoscope of the same brand were used for BP measurements. The VI Brazilian Guidelines on Hypertension (SBC / BHS protocol / SBN 2010) were strictly followed (SBC/ SBH/ SBN 2010).

\section{Autonomic activity}

Measurements of autonomic activity were performed to evaluate the effect of this variable on blood pressure responses to exercise and on vitamin D supplementation. Autonomic activity was measured before and 
after exercise sessions (during the 60-minute recovery in intervals of 10 minutes) and always after the blood pressure measurements, each recording lasted five minutes. This variable was determined by recording the variability of the RR interval heart rate and autonomic balance LF / HF using a heart rate monitor Polar RS800 CX (Polar, Finland). The analysis was performed in the time domain (mean and standard deviation of RR intervals) and the frequency domain, with a low frequency band indicating sympathetic activity and high frequency band indicating parasympathetic activity, beyond the sympathovagal balance.

\section{Data analysis}

Data are expressed as the mean and the standard error of the mean. The normality and homogeneity of the data were previously evaluated by the Shapiro-Wilks and Levene tests, respectively. To compare the magnitude of post-exercise hypotension and the heart rate measurements, the subjective perception of effort and the cardiac autonomic nervous activity, it was used an analysis of variance (ANOVA - two way) with Tukey's post hoc test $p<0.05$ was considered statistically significant. All tests were performed in Instat software, version 3.0.

\section{RESULTS}

The baseline characteristics of the participants of this study are presented in Table I. The participants were hypertensive and used one or two class of antihypertensive drugs (diuretics, beta-blockers and inhibitors of the angiotensinconverting enzyme). All of them were sedentary, were not diagnosed with diabetes, and they did not drink alcohol or smoke. The two groups had an overweight nutritional status and a high percentage of fat. The resting $\mathrm{BP}$ was controlled. The serum 25(OH)D values found in the population corresponded to vitamin D insufficiency. The two groups were statistically similar for each of these variables.

During the session of exercise, the subjective perception of effort assessed by the Borg \& Noble (1974) scale ranged between $11.09 \pm 0.09$ and $11.54 \pm 0.20$ in the experimental group and $11.0 \pm 0.1$ and $12.0 \pm 0.3$ in the placebo group, with no difference between groups ( $p>0.05)$ (Figure 2). The HR increased from $80.5 \pm 2.8 \mathrm{bpm}$ at rest to $94.9 \pm 6.7 \mathrm{bpm}$ at the end of exercise in the experimental group and $88 \pm 4.1 \mathrm{bpm}$ to $95.6 \pm 4.7$ $\mathrm{bpm}$ in the placebo group, with no differences between the two groups ( $p>0.05$ ) (Figure 2).

As shown in Figure 3 , the resting SBP decreased from $127.8 \pm 6.8 \mathrm{mmHg}$ (day Pre supplementation) to $122 \pm 6.7 \mathrm{mmHg}$ (day 5, five days after supplementation) in the experimental group, but without significant difference ( $p>0.05)$. Moreover, the values returned to $129.1 \pm$ $6.5 \mathrm{mmHg}$ at seven days after supplementation (day 7), also without significant difference $(p>0.05)$. Meanwhile, no changes were noted in the resting SBP in the placebo group.

Regarding the resting DBP, a slight and nonsignificant increase in the experimental group from $64.7 \pm 3.5 \mathrm{mmHg}$ (day 1) to $68.5 \pm 3.3 \mathrm{mmHg}$ (day 5) was observed, and this increase continued to $72.1 \pm 4.1 \mathrm{mmHg}$ on day 7 . The resting DBP of the placebo group did not change (Figure 3 ).

The exercise session in the placebo group promoted significant systolic $\mathrm{PEH}$ at $20 \mathrm{~min}$ $(-10.8 \pm 2.0 \mathrm{mmHg}), 40 \mathrm{~min}(12.4 \pm 2.5 \mathrm{~mm} \mathrm{Hg})$, $50 \mathrm{~min}(-13.6 \pm 2.9 \mathrm{mmHg})$ and $60 \mathrm{~min}(-11.6 \pm$ $2.8 \mathrm{mmHg}$ ) post-exercise, which is expected from a workout effect (Figure 4). However, in the experimental group under the effect of vitamin D supplementation, significant systolic PEH occurred only at 20 minutes post-exercise $(-8.0 \pm 3.1 \mathrm{mmHg})$. Furthermore, the experimental 
procedure limited the systolic PEH at all times when compared to that of the placebo group because the statistical significance observed in the placebo group did not exist in the experimental group. Additionally, this minimization of PEH was close to or above $50 \%$ at virtually all times (except at 20 min post exercise). Despite this phenomenon, significant differences between the groups were not observed (Figure 4).

A similar behavior was observed for the diastolic PEH, which the values were higher in the placebo group (between $-5.6 \pm 2.6 \mathrm{mmHg}$ at 10 minutes post-exercise and $-4.0 \pm 3.5 \mathrm{mmHg}$ at 60 minutes post-exercise) than in the experimental group but without significant differences, which experienced PEH only at 20 minutes $(-1.5 \pm 2.9$ $\mathrm{mmHg}$ ) and 40 minutes post-exercise (-1.1 \pm $2.5 \mathrm{mmHg}$ ), also with no significant difference (Figure 4).

In relation to autonomic modulation, it can be observed in Figure 5 that there was no significant change in the average RR interval between the experimental and placebo groups, and none of the other variables was altered in the time domain (data not shown). On the other hand, when the cardiac autonomic nervous activity was evaluated in the frequency domain, there was a significant increase in the values of LF / HF in the experimental group at 20 (3.11 $\pm 0.86 \mathrm{~m} / \mathrm{s} 2), 40(3,63 \pm 1.03 \mathrm{~m} / \mathrm{s} 2), 50$ (3.51 $\pm 1.18 \mathrm{~m} / \mathrm{s} 2)$ and 60 minutes (3.69 $\pm 1.14 \mathrm{~m} /$ s2) when compared to that at rest (1.25 \pm 0.35 $\mathrm{m} / \mathrm{s} 2$ ), and it did not occur in the placebo group. In this group, the values of LF / HF did not significantly increase compared to that at rest $(1.88 \pm 0.42 \mathrm{~m} / \mathrm{s} 2)$, ranging from $2.14 \pm 0.48$ $\mathrm{m} / \mathrm{s} 2$ at 10 minutes to $2.85 \pm 0.86 \mathrm{~m} / \mathrm{s} 2$ at 60 minutes post-exercise. Despite this increase in the sympathovagal balance observed in the experimental group, the post-exercise values did not differ from placebo.

\section{DISCUSSION}

The present study evaluated whether an acute megadose of vitamin $D$ reduces resting blood pressure and potentiate the post exercise hypotension of elderly hypertensive women.
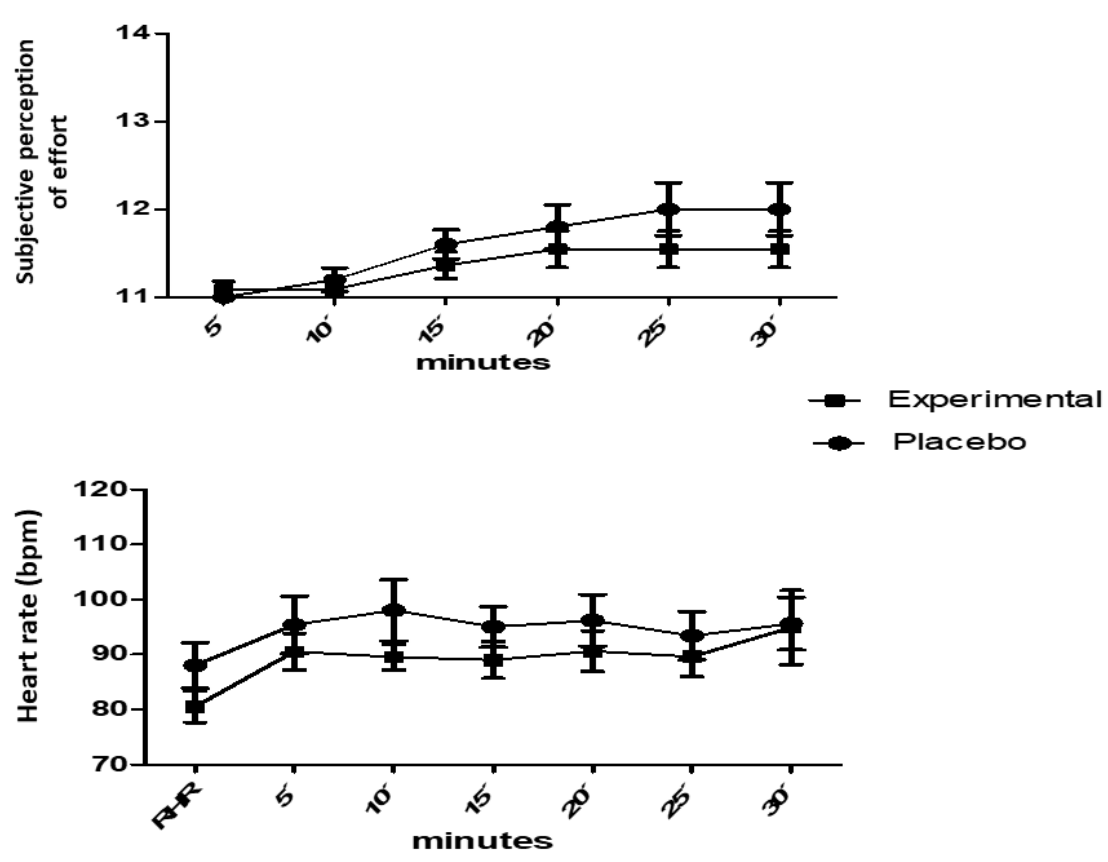

Figure 2. Subjective perception of effort and heart rate during the exercise protocol in the placebo and supplemented (experimental) procedures. RHR (resting heart rate). Data are presented as mean and standard error of the mean. No statistical differences were found ( $p>0.05$ ). 


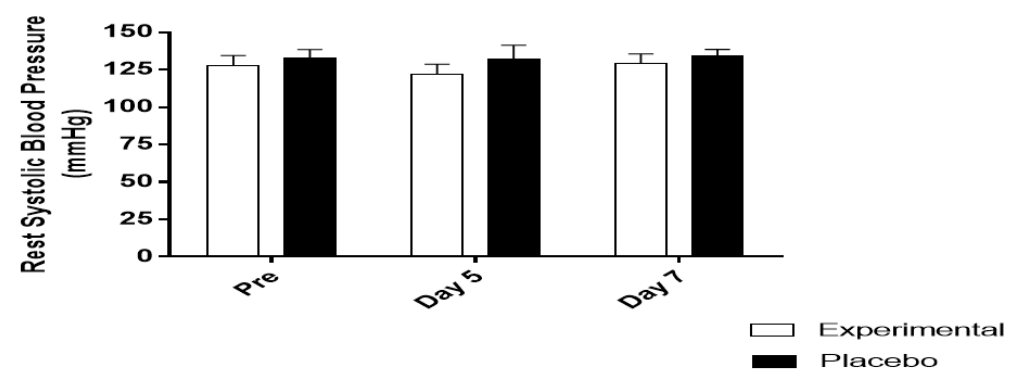

Figure 3. Rest systolic and diastolic blood pressure in the three measurement occasions. Data are presented as mean and standard error of the mean. No statistical difference observed ( $p>0.05)$.
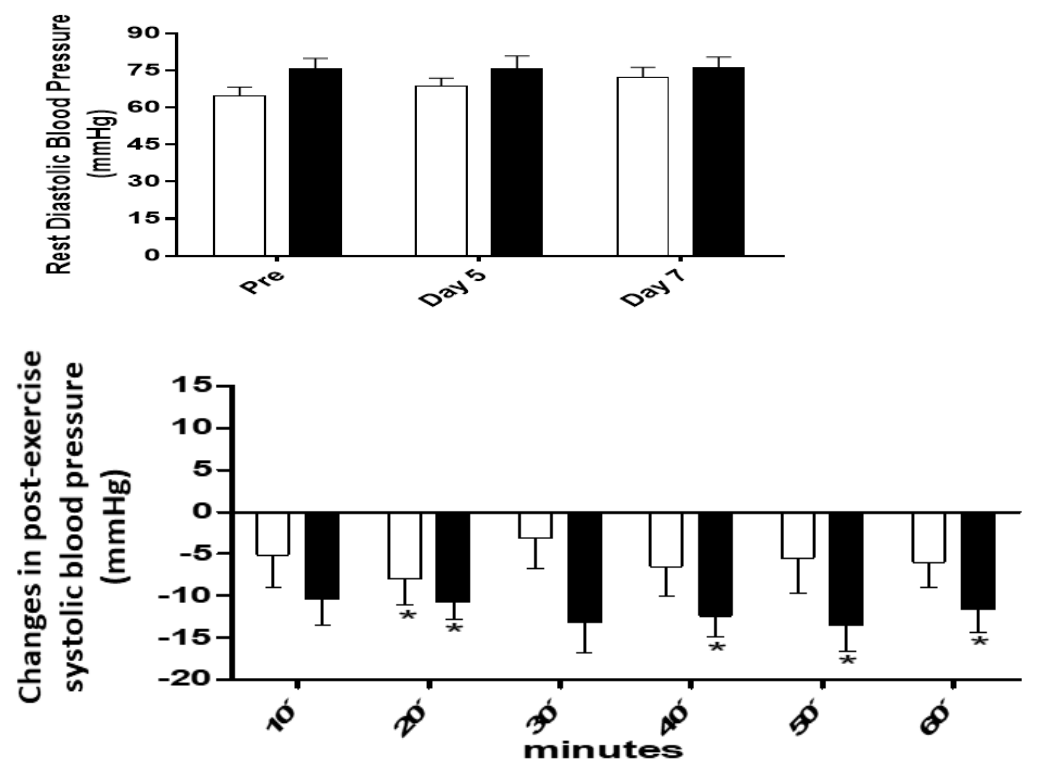

Figure 4.

Changes in systolic and diastolic blood pressure during the 60 minutes post exercise. Data are presented as mean and

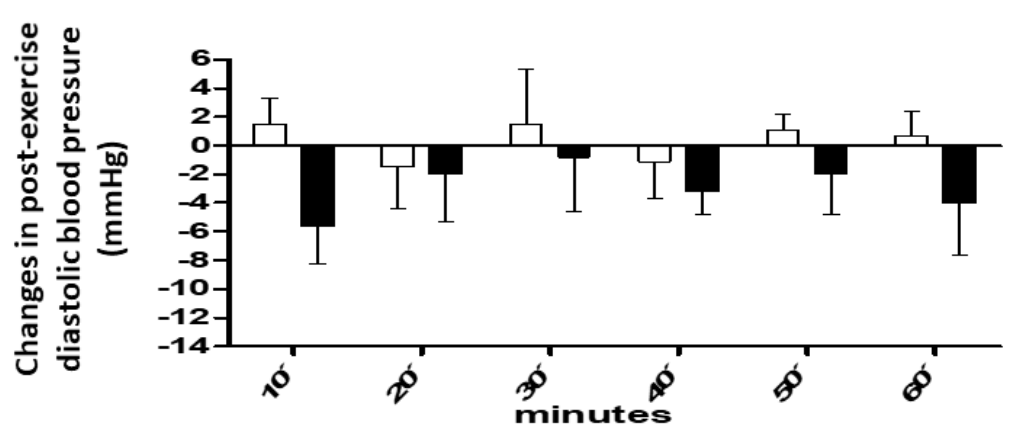

Experimental Placebo

standard error of the mean. *Significant reduction compared to baseline $(p<0.05)$.

Contradicting our initial hypothesis, our data showed that vitamin $\mathrm{D}$ is not able to promote RBP reduction for at least the first 5 and 7 days after supplementation with a megadose and promoted a deleterious effect by inhibiting the PEH. The exercise session in the placebo group promoted significant systolic PEH at four moments post-exercise, however, in the experimental group under the effect of vitamin
D supplementation, significant systolic PEH occurred only at one moment post-exercise, which was accompanied by an unwanted increase in the inflow of sympathetic vagal balance to the heart at $20 \mathrm{~min}, 40 \mathrm{~min}, 50 \mathrm{~min}$ and 60 min post exercise.

The fifth day BP data, however, should be reviewed with caution, since the subsequent calculation revealed an effect size of 1.01 

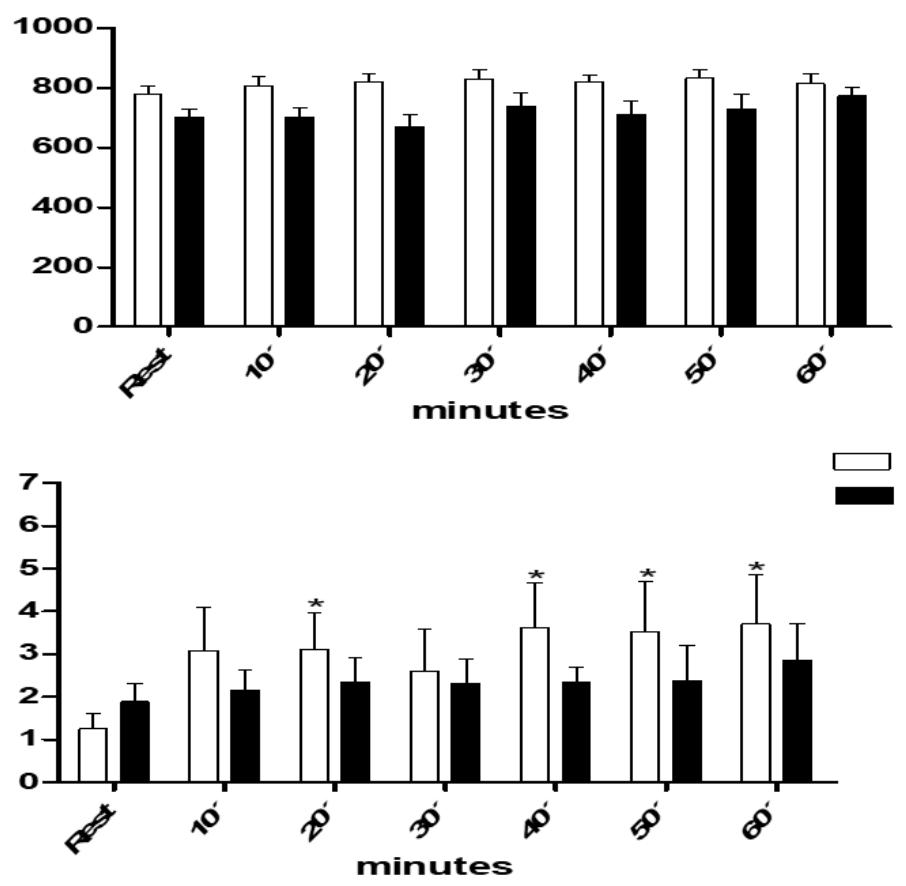

Figure 5. Autonomic modulation represented by the mean of the R-R interval and the autonomic balance LF/HF in the placebo and experimental groups. Data are presented as mean and standard error of the mean. *Significant difference in relation to the rest $(p<0.05)$.

Table I. Characterization of participants from experimental and placebo groups.

\begin{tabular}{|c|c|c|c|}
\hline & Experimental $(N=11)$ & Placebo $(N=5)$ & p value \\
\hline Age (years) & $70.3 \pm 1.7$ & $72.4 \pm 1.2$ & 0.46 \\
\hline Body weight (Kg) & $66.4 \pm 3.8$ & $66.1 \pm 4.6$ & 0.96 \\
\hline BMI $\left(\mathrm{Kg} / \mathrm{m}^{2}\right)$ & $28.8 \pm 1.6$ & $28.2 \pm 2.0$ & 0.85 \\
\hline$\%$ of fat & $39.4 \pm 1.5$ & $37.3 \pm 1.9$ & 0.46 \\
\hline 25(OH)D (ng/ml) & $24.1 \pm 1.1$ & $21.9 \pm 1.2$ & 0.29 \\
\hline SBP of rest (mmHg) & $127.8 \pm 6.8$ & $132.0 \pm 6.0$ & 0.70 \\
\hline DBP of rest (mmHg) & $64.6 \pm 3.6$ & $75.6 \pm 4.3$ & 0.13 \\
\hline
\end{tabular}

BMI (body mass index), SBP (systolic blood pressure), DBP (diastolic blood pressure) and 25 (OH) D (25- hydroxyvitamin D). Data presented as mean and standard error of the mean. No statistical differences between groups $(p>0.05)$.

for systolic pressure, which is considered expressive (Eng 2003). Interestingly, blood pressure on the seventh day, however, increased to values descriptively above baseline. It should be mentioned that this measure of BP in the seventh day was made moments before the exercise protocol, so that it is possible to suppose with some degree of evidence that the elderly presented this value because of the pre-exercise expectation, thus, the measure of resting $\mathrm{BP}$ on the fifth day is more reliable than the seventh day.

Intervention studies indicated that vitamin D supplementation resulted in a reduction in BP, as demonstrated in a meta-analysis published by $\mathrm{Wu}$ et al. (2010) which showed a reduction of $2.44 \mathrm{mmHg}$ in SBP after oral administration of vitamin D. However, this reduction in blood pressure is not consensual. Despite the RDA (Recommended Dietary Allowance) indicates a daily intake of 600 IU for women between 51 and 
70 years and $800 \mathrm{IU}$ for women over 70 years (IOM 2010) megadoses of 100.000 and 200.000 IU have been used (Scragg et al. 2014). For this reason, a megadose of 200.000 IU was adopted in this study. This megadose did not alter resting SBP or DBP.

Unlike our data, Larsen et al. (2012) found a significant reduction in SBP and DBP after 20 weeks of treatment with a daily intake of 3.000 IU of vitamin D in 92 hypertensive patients (61 \pm 10 years) who had hypovitaminosis D. Goel \& Lal (2011) compared the response of two groups of hypertensive patients, a group receiving antihypertensive drugs and a group receiving 33.000 IU of vitamin D every two weeks for 3 months, and more significant reduction in SAP was observed in the group that received vitamin D compared to the medicated group ( $p<0.05)$. Alagacone et al. (2019) confirmed that there is an association between resistant hypertension and vitamin D, because the deficiency of this vitamin was associated with resistant hypertension with Odds Ratio (OR) of $3.5(95 \%$ Cl 1.69-7.17) p $=0.009$ in this study.

On the other hand, Scragg et al. (2014) also used 200.000 IU of vitamin D for 2 months and 100,000 IU for 18 months and observed no significant changes between SBP and DBP measured at the first, fifth and eighteenth month of the study. Similarly, Witham (2013) supplemented 159 hypertensive subjects with 100,000 IU of vitamin D every 3 months for one year, and when compared with a placebo group, they did not observe a significant improvement in blood pressure levels. Zaleski et al. (2018) suggest that circulating 25(OH) D levels do not appear to be related to the peak exercise systolic blood pressure response to maximal exercise among healthy individuals. Subjects with sufficient $25(\mathrm{OH})$ D had higher resting systolic blood pressure $(120 \pm 14 \mathrm{mmHg}$ vs. $117 \pm 13 \mathrm{mmHg} ; p=0.020$ ) than individuals with insufficient $25(\mathrm{OH})$ D. In contrast to initial hypothesis, 25(OH) D levels were not associated with the peak systolic blood pressure. Baseline $25(\mathrm{OH})$ D levels were positively correlated with resting systolic blood pressure, however, the magnitude of this effect is likely not clinically meaningful.

One possible explanation for the differences in the results of these studies is the form of administration. While in our study and in other studies, where researchers have adopted a single megadose from 100.000 IU to 200.000 IU, there was no reduction in blood pressure, there were blood pressure reductions in studies that used multiple administrations of lower doses (40 to 33.000 IU / day for 8 to 24 weeks) (Witham et al. 2009, Pardono et al. 2012). It is known that the initial level of blood pressure is a determinant of the magnitude of the hypotensive responses (Forjaz et al. 2000), which may also explain the differences in the results of the studies. Finally, our study was done with the elderly, who may respond differently to treatment because of changes in the absorption and metabolism processes of ingested substances (Lanske \& Razzaque 2007).

An interesting phenomenon observed in our study was that in addition to not promoting a reduction in resting blood pressure, a megadose of 200.000 IU still inhibited the magnitude of systolic PEH. Data from this study indicates that PEH systolic values in the placebo group ranged from $-10.4 \pm 3.0$ to $-11.6 \pm 2.8 \mathrm{mmHg}$ during the recovery period, corroborating with prior literature on the subject, which reports that workout promotes blood pressure reductions from 8 to $20 \mathrm{mmHg}$ for the systolic component and 2 to $10 \mathrm{mmHg}$ for the diastolic component (Cardoso et al. 2010). This magnitude of reduction in blood pressure after exercise places physical training as an antihypertensive treatment with efficacy comparable to currently available drugs 
(Lopes et al. 2018). However, vitamin D reduced $\mathrm{PEH}$ to values between $-5.1 \pm 3.8$ and $-6.0 \pm 2.9$ $\mathrm{mmHg}$, which is lower than the values found in previous literature.

At the moment we have no way to determine how vitamin D could be limiting the hypotensive response after exercise. However, thankfully, we monitored the cardiac autonomic nervous activity, which allowed us to realize that the inhibition of PEH was accompanied by an increase in the autonomic balance, which indicates a greater sympathetic outflow or a reduced influence of parasympathetic outflow to the heart. This phenomenon is precisely the opposite of what is expected of an exercise session, which would be a reduction of the sympathovagal balance (Anunciação \& Polito 2011, Laterza et al. 2007). Although not yet fully understood, it is known that decrease in cardiac output, histamine receptor activation and peripheral vasodilation also play a role in PEH (Halliwill et al. 2013). Therefore, although the data from this study did not fully clarify how vitamin D could inhibit the PEH, we were able to determine that at least a negative increase in autonomic balance seems to be part of this process.

Considering previous studies showing that doses lower than 200.000 IU of vitamin D repeated for several weeks result in a reduction of $\mathrm{BP}$ at rest, we cannot be conclusive in affirming that supplementation of vitamin D inhibits PEH. It is important to notice that the effect observed in this study was obtained with a supplementation of a single megadose. Thus, the practical implication of this study is the need for methodological procedure repetition, in these cases, adding protocols with different doses of vitamin D, sustaining the hypothesis that repeated minor doses may enhance the PEH or at least avoid the inhibitory effect observed in this study and with a larger sample, therefore, the results of the present study are still not enough to modify the existing clinical practice. If the hypotheses are confirmed more robustly, these results may have a more significant impact on the clinical decisions, as we would be showing to the scientific community and professionals in the area, a new micronutrient that compromises the control of the blood pressure of the elderly hypertensive and which also impairs the hypotensive capacity of the physical exercise.

An important clinical implication raised from this study was that although benefits have been seen with megadose of vitamin $D$ supplementation, at least in this case of elderly populations, this supplementation does not improve resting blood pressure and still impaired hemodynamics responses to exercise. Obviously, the character of a pilot study still needs to be better confirmed, but this data should already provide caution in clinical practice regarding megadose vitamin D supplementation in this population.

The limitation of this study was a not statistically determined sample size. In order to solve doubts regarding the ability of the sample size to answer the study question, a posteriori effect size calculation was performed, which revealed a value of 1.01 and a minimum sample size of eight subjects for resting blood pressure. Thus, our sample size of the experimental group is support by the study. Other fact to be considered is that both the resting $\mathrm{BP}$ and the PEH were measured after at most seven days after supplementation. Therefore, in future studies, we recommend that these measures are performed for longer periods of time to establish a certainty that some laggard effect would not occur.

We can conclude that a supplementation with a single megadose of 200.000 IU of vitamin $D$ did not decreased the resting BP of elderly volunteers after seven days. For the first time, it 
was demonstrated that this megadose promotes a deleterious effect by partially inhibiting the $\mathrm{PEH}$ reduction, which was accompanied by an unwanted increase in the inflow of sympathetic vagal balance to the heart. Therefore, data from this study suggest caution in the clinical practice of vitamin D megadose supplementation for the elderly population.

\section{Acknowledgments}

We thank the Universidade Federal da Paraiba for the support for this study. We also thank each co-author for collaborations at all stages of the research.

\section{REFERENCES}

ALAGACONE S, VERGA E, VERDOLINI R \& SAIFULLAH SM. 2019. The association between vitamin D deficiency and the risk of resistant hypertension. Clinical and Experimental Hypertension 2: 1-4.

ANUNCIAÇÃO PG \& POLITO MD. 2011. A review on postexercise hypotension in hypertensive individuals. Arq Bras Cardiol 96(5): e100-e109.

BORG GAV \& NOBLE BJ. 1974. Perceived exertion. in: Wilmore $J H(E d)$, Exercise and sport sciences reviews. Academic Press 2: 131-153.

BRITO AF, ALVES NF, ARAÚJO AS, GONÇALVES MC \& SILVA AS. 2011. Active intervals between sets of resistance exercises potentiate the magnitude of postexercise hypotension in elderly hypertensive women. J Strength Cond Res 25(11): 3129-3136.

BRITO LC, QUEIROZ ACC \& FORJAZ CLM. 2014. Influence of population and exercise protocol characteristics on hemodynamic determinants of post-aerobic exercise hypotension. Braz J Med Biol Res 47(8):626-636.

BRUYÉRE O, CAVALIER E, SOUBERBIELLE JC, BISCHOFF-FERRARI HA, BEAUDART C, BUCKINX F, REGINSTER JY \& RIZZOLI R. 2014. Effects of vitamin $d$ in the elderly population: current status and perspectives. Arch Public Health 72(1): 32.

CARDOSO CG, GOMIDES RS, QUEIROZ AC, PINTO LG, LOBO F, TINUCCI T, MION D JR \& FORJAZ CL. 2010. Acute and chronic effects of aerobic and resistance exercise on ambulatory blood pressure. Clinics (Sao Paulo) 65(3): 317-325.

ENG MDJ. 2003. Sample size estimation: how many individuals should be studied? Radiology 227(2): 309-313.
FORJAZ CL, TINUCCI T, ORTEGA KC, SANTAELLA DF, MION JR D \& NEGRÃO CE. 2000. Factors affecting post-exercise hypotension in normotensive and hypertensive humans. Blood Press Monit 5(5-6): 255-262.

FORMAN JP. 2007. Plasma 25-hydroxivitamin d levels and risk incident hypertension. Hypertension 49(5): 1063-1069.

GELEIJNSE JM. 2010. Vitamin $d$ and the prevention of hypertension and cardiovascular diseases: a review of the current evidence. Am J Hypertens 24(3): 253-62.

GOEL RK \& LAL H. 2011. Role of vitamin d supplementation in hypertension. Indian J Clin Biochem 26(1): 88-90.

HALLIWILL JR, BUCK TM, LACEWELL AN \& ROMERO SA. 2013. Postexercise hypotension and sustained postexercise vasodilatation: what happens after we exercise? Exp Physiol 98(1): 7-18.

HOLICK MF. 2007. Vitamin d deficiency. N Eng. J Med 357(3): 266-281.

HOLICK MF, BINKLEY NC, BISCHOFF-FERRARI HA, GORDON CM, HANLEY DA, HEANEY RP, MURAD MH \& WEAVER CM. 2011. Evaluation, treatment, and prevention of vitamin D deficiency: an Endocrine Society clinical practice guideline 96(7): 1911-1930.

HOLICK MF \& CHEN TC. 2008. Vitamin d deficiency: a worldwide problem with health consequences. Am J Clin Nutr 87(4): 1080s-1086s.

IOM - INSTITUTE OF MEDICINE. 2010. Dietary reference intakes: applications in dietary assessment. washington, dc: national academy press.

JUDD SE, RAISER SN, KUMARI M \& TANGPRICHA V. 2010. 1,25-dihydroxyvitamin d (3) Reduces systolic blood pressure in hypertensive adults: a pilot feasibility study. J Steroid Biochem Mol Biol 121: 445-447.

KE L, MASON RS, KARIUKI M, MPOFU E \& BROCK KE. 2015. Vitamin D status and hypertension: A review. Integr Blood Press Control 8(8): 13-35.

KUNUTSOR SK, BURGESS S, MUNROE PB \& KHAN H. 2014. Vitamin D and high blood pressure: causal association or epiphenomenon? Eur J Epidemiol 29(1): 1-14.

LANSKE B \& RAZZAQUE MS. 2007. Vitamin D and aging: old concepts and new insights. J Nutr Biochem 18: 771-777.

LARSEN T, MOSE FH, BECH JN, HANSEN AB \& PEDERSEN EB. 2012. Effect of cholecalciferol supplementation during winter months in patients with hypertension: a randomized, placebo-controlled trial. Am J Hypertens 25(11): 1215-1222. 
LATERZA MC, BRANDÃO RMUP \& NEGRÃO CE. 2007. Efeito anti-hipertensivo do exercício. revista brasileira de hipertensão 14(2): 104-111.

LIMA FEL, SLATER B, LATORRE MRDO \& FISBERG RM. 2007. Validity of a quantitative food frequency questionnaire developed for women in the Northeast of Brazil. Rev Bras Epidemiol 10(4): 483-489.

LIPS P \& VAN SCHOOR NM. 2011. The effect of vitamin d on bone and osteoporosis. Best Pract Res Clin Endocrinol Metab 25(4): 585-591.

LOPES S, MESQUITA-BASTOS J, ALVES AJ \& RIBEIRO F. 2018. Exercise as a tool for hypertension and resistant hypertension management: current insights. Integr Blood Press Control 20 (11): 65-71.

MILES D. 2010. The effects of vitamin d supplementation on physical function and quality of life in older patients with heart failure: a randomized controlled trial. Circ Heart Fail 3(2): 195-201.

NEVES JP, SILVA AS, MORAIS LC, DINIZ ADAS, COSTA MJ, ASCIUTTI LS \& GONÇALVES MDAC. 2012. 25-hydroxyvitamin d concentrations and blood pressure levels in hypertensive elderly patients. Arq Bras Endocrinol Metabol 56(7): 415-422.

PARDONO E, ALMEIDA MB, BASTOS AA \& SIMÕES HG. 2012. Post-exercise hypotension: possible relationship with ethnic and genetic factors. Rev Bras Cineantropom Desempenho Hum 14(3): 353-361.

SBC/ SBH/ SBN - SOCIEDADE BRASILEIRA DE CARDIOLOGIA, SOCIEDADE BRASILEIRA DE HIPERTENSÃO, SOCIEDADE BRASILEIRA DE NEFROLOGIA. 2010. VI diretrizes brasileiras de hipertensão arterial. Arq Bras Cardiol 95(supl.1): 1-51.

SCHUCH NJ, GARCIA VC \& MARTINI LA. 2009. Vitamina D e doenças endocrinometabólicas. Arq Bras Endocrinol Metab 53(5): 625-633.

SCRAGG R, SLOW S, STEWART AW, JENNINGS LC, CHAMBERS ST, PRIEST PC, FLORKOWSKI CM, CAMARGO JR CA \& MURDOCH DR. 2014. Long-term high-dose vitamin d3 supplementation and blood pressure in healthy adults: a randomized controlled trial. Hypertension 64(4): 725-730.

WITHAM MD. 2013. Cholecalciferol treatment to reduce blood pressure in older patients with isolated systolic hypertension: the vitdish randomized controlled trial. Jama Intern Med 173(18): 1672-1679.

WITHAM MD, NADIR MA \& STRUTHERS AD. 2009. Effect of vitamin d on blood pressure: a systematic review and meta-analysis. J Hypertens 27(10): 1948-1954.
WU SH, HO SC \& ZHONG L. 2010. Effects of vitamin d supplementation on blood pressure. South Med J 103(8): 729-737.

ZALESKI A, TAYLOR B, ARMSTRONG B, PUGLISI M, CLARKSON P, CHIPKIN S, WHITE CM, THOMPSON PD \& PESCATELLO LS. 2018. Associations of 25-Hydroxyvitamin D With the Blood Pressure Response to Maximal Exercise Among Healthy Adults. Int J Sport Nutr Exerc Metab 17: 1-6.

\section{How to cite}

GONÇALVES MCR, MIRANDA NETO M, CAVALCANTE IGM, SEBADELHE VRRJ, SOUZA MF, NEVES JPR, SOUZA FTL, TAVARES RL, COSTA MS \& SILVA AS. 2020200.000 IU of vitamin D does not reduce resting Blood Pressure and Inhibit Post-Exercise Hypotension in elderly women: a pilot study. An Acad Bras Cienc 92: e20190227. DOI 10.1590/0001-3765202020190227.

Manuscript received on February 22, 2019;

accepted for publication on June 5, 2019

MARIA DA CONCEIÇÃO R. GONÇALVES ${ }^{2}$

https://orcid.org/0000-0001-7223-8470

MANOEL MIRANDA NETO

https://orcid.org/0000-0002-5262-980X

ISA G.M. CAVALCANTE ${ }^{1}$

https://orcid.org/0000-0001-9422-8599

VITTÓRIA R.R.J. SEBADELHE ${ }^{1}$

https://orcid.org/0000-0003-3280-2641

MICHELE F. DE SOUZA ${ }^{1}$

https://orcid.org/0000-0002-5850-1305

JULIANA P.R. NEVES ${ }^{1}$

https://orcid.org/0000-0002-2569-0074

FLAVIA T.L. DE SOUZA ${ }^{1}$

https://orcid.org/0000-0002-8696-4307

RENATA L. TAVARES ${ }^{1,2}$

https://orcid.org/0000-0002-8049-2708

MATHEUS S. COSTA ${ }^{1}$

https://orcid.org/0000-0002-1723-7317

\section{ALEXANDRE S. SILVA ${ }^{1,2}$}

https://orcid.org/0000-0003-3576-9023

${ }^{1}$ Laboratório de Estudos do Treinamento Físico Aplicado ao Desempenho e a Saúde, Centro de Ciências da Saúde, Universidade Federal da Paraíba, Campus I, Cidade Universitária, 58051-900 João Pessoa, PB, Brazil 
${ }^{2}$ Programa de Pós-Graduação em Ciências da Nutrição, Centro de Ciências da Saúde, Universidade

Federal da Paraíba, Campus I, Cidade Universitária,

58059-900 João Pessoa, PB, Brazil

Correspondence to: Alexandre Sérgio Silva

E-mail: alexandresergiosilva@yahoo.com.br

\section{Author contributions}

Initially, the conception and design of the study idea was done by Maria da Conceição Rodrigues Gonçalves and Juliana Padilha Ramos Neves, later the data collection was performed by Manoel Miranda Neto, Michele Frazão de Souza and Flavia Tavares Leite de Souza. After this phase, the stage of data tabulation, statistical analysis and writing of the manuscript was started, being performed by Manoel Miranda Neto, Isa Gabriela de Medeiros Cavalcante, Vittória Regina Rodrigues Jacob Sebadelhe, Renata Leite Tavares, Matheus da Silveira Costa and Alexandre Sérgio Silva. Before submission, the final revision of the manuscript was made by Maria da Conceição Rodrigues Gonçalves and Alexandre Sérgio Silva.

(cc) BY 